\title{
Warm Pre-Strain: Strengthening the Metastable 304L Austenitic Stainless Steel without Compromising Its Hydrogen Embrittlement Resistance
}

\author{
Yanfei Wang ${ }^{1, *}$, Zhiling Zhou ${ }^{1}$, Weijie $\mathrm{Wu}^{2}$ and Jianming Gong ${ }^{2}$ \\ 1 School of Chemical Engineering \& Technology, China University of Mining and Technology, Xuzhou 221116, \\ China; 283375421@163.com \\ 2 School of Mechanical and Power Engineering, Nanjing Tech University, Nanjing 211816, China; \\ stephen_nj@163.com (W.W.); gongjm@njtech.edu.cn (J.G.) \\ * Correspondence: wyf709903@163.com; Tel./Fax: +86-0516-8359-1060
}

Received: 12 October 2017; Accepted: 17 November 2017; Published: 21 November 2017

\begin{abstract}
Plastic pre-strains were applied to the metastable 304L austenitic stainless steel at both room temperature $\left(20^{\circ} \mathrm{C}\right)$ and higher temperatures (i.e., 50,80 and $\left.100^{\circ} \mathrm{C}\right)$, and then the hydrogen embrittlement (HE) susceptibility of the steel was evaluated by cathodically hydrogen-charging and tensile testing. The $20^{\circ} \mathrm{C}$ pre-strain greatly strengthened the steel, but simultaneously significantly increased the HE susceptibility of the steel, since $\alpha^{\prime}$ martensite was induced by the pre-strain, causing the pre-existence of $\alpha^{\prime}$ martensite, which provided "highways" for hydrogen to transport deep into the steel during the hydrogen-charging. Although the warm pre-strains did not strengthen the steel as significantly as the $20{ }^{\circ} \mathrm{C}$ pre-strain, they retained the HE resistance of the steel. This is because the higher temperatures, particularly 80 and $100{ }^{\circ} \mathrm{C}$, suppressed the $\alpha^{\prime}$ martensite transformation during the pre-straining. Pre-strain at a temperature slightly higher than room temperature has a potential to strengthen the metastable 304L austenitic stainless steel without compromising its initial HE resistance.
\end{abstract}

Keywords: hydrogen embrittlement; austenitic stainless steels; pre-strain; martensite transformation

\section{Introduction}

Due to good hydrogen embrittlement (HE) resistance, austenitic stainless steels (ASSs) have been widely used in the hydrogen-containing environments of chemical and petrochemical industries. Nowadays, they are further considered as one of the candidate materials for pressure vessels or liners storing and transporting gaseous or liquid hydrogen for the upcoming hydrogen energy industry [1-3]. However, the ASSs can be embrittled by hydrogen with varying degree seemingly depending on their stability against strain-induced $\alpha^{\prime}$ martensite transformation. That is, the stable ASSs, e.g., 310S, in which no $\alpha^{\prime}$ martensite forms during strain, are found less sensitive to hydrogen [3-5], while the metastable ones, e.g., 304L, which undergo the transformation from $\gamma$ austenite to $\alpha^{\prime}$ martensite during strain, can be severely embrittled by hydrogen [3,4,6-10]. Although the exact role of strain-induced $\alpha^{\prime}$ martensite in the HE mechanism of ASSs is still unclear (e.g., is the austenite itself embrittled or is the strain-induced $\alpha^{\prime}$ martensite embrittled), many researchers have accepted that the induced $\alpha^{\prime}$ martensite can provide "highways" for hydrogen transport in the ASSs [7-9], consequently increase their HE susceptibility.

ASS components, e.g., vessels and liners, often inevitably suffer from some degree of plastic deformation during fabrication, such as tension, bending, stretching and drawing. Most of these deformations are carried out at room temperature. Moreover, since the ASSs at the solution-annealed state possess excellent plasticity but lower yield strength, cold-stretching technique [11-13] has been 
applied to them purposely to elevate their strength based on the concept of strain-strengthening (work-hardening). For example, for a pressure vessel, the cold-stretching technique is generally performed at room temperature by pressurizing the vessel to a pressure known to produce required amount of plastic deformation [12]. The vessel then becomes stronger due to strain-strengthening to withstand a service pressure with reduced wall thickness, hence saving the materials and reducing the weight. The cold-stretching technique has been involved in several standards, e.g., EN 13458-2 Appendix C [14], AS 1210 Supplement 2 [15], and ASME Code Case 2596 [16]. However, the prior plastic deformations can induce $\alpha^{\prime}$ martensite transformation in the metastable ASSs, causing the pre-existence of $\alpha^{\prime}$ martensite before hydrogen exposure. Many studies have shown that the pre-existing $\alpha^{\prime}$ martensite can enhance the hydrogen transport and thus decrease the HE resistance of ASSs. For instance, Perng and Altstetter [17] showed that, in the metastable 301 and 304 steels, the diffusivity and permeability of hydrogen were greatly enhanced by increasing pre-strain-induced $\alpha^{\prime}$ martensite. Mine et al. [18] found that the fatigue crack growth rate was more sensitive to hydrogen in the pre-strained 304 steels since $\alpha^{\prime}$ martensite had been created by the pre-strain. On the contrary, the more stable ASSs were found to be less affected by the pre-strain, since little or no $\alpha^{\prime}$ martensite was induced by the pre-strain $[17,18]$. Martin et al. [19] revealed a detrimental effect of machining-induced $\alpha^{\prime}$ martensite on the performance of 304 steel in hydrogen. Wang et al. [20] found that, since the volume fraction of induced $\alpha^{\prime}$ martensite increased with increasing pre-strain, a higher level of pre-strain resulted in higher hydrogen diffusivity and more severe HE in the $304 \mathrm{~L}$ steel. Thus, it is indicated that, when applying the cold pre-strain to the metastable ASSs, more attention should be paid to its negative effect on HE resistance due to strain-induced $\alpha^{\prime}$ martensite transformation.

It is known that the transformation from $\gamma$ austenite to $\alpha^{\prime}$ martensite in the metastable ASSs depends on the temperature at which the strain is applied. For the most widely-used 304 and 304L ASSs, it is found that, pre-straining at the temperatures close to room temperature can induce $\alpha^{\prime}$ martensite transformation in the steels, but elevating the pre-strain temperature can make the transformation less severe [21-23]. Considering that, a higher temperature can suppress the $\alpha^{\prime}$ martensite transformation in the 304L ASS, we are motivated to examine whether we can apply the prior plastic deformation, or the cold-stretching technique, to the metastable 304L ASS at a temperature slightly higher than room temperature, without inducing severe $\alpha^{\prime}$ martensite transformation, thus preserving its original good HE resistance. In fact, a pre-strain at a slightly elevated temperature can still be able to strengthen the metastable ASSs. Therefore, in this paper, we pre-strained the metastable ASS 304L by tension at various temperatures, i.e., 20 (room temperature), 50, 80 and $100{ }^{\circ} \mathrm{C}$, and then evaluated its $\mathrm{HE}$ susceptibility by cathodically hydrogen pre-charging and tensile testing.

\section{Materials and Experimental}

The 304L steel used has a chemical composition of Fe-0.02C-0.37Si-1.15Mn-0.004S-0.031P-18.3Cr$8.1 \mathrm{Ni}-0.044 \mathrm{~N}-0.014 \mathrm{Mo}-0.064 \mathrm{Cu}, \mathrm{wt} \%$. It was received in the form of a $10 \mathrm{~mm}$ thick plate and was solution-annealed at $1080^{\circ} \mathrm{C}$ for $1 \mathrm{~h}$ and water quenched. $\mathrm{The}^{\mathrm{Md}} \mathrm{d}_{30}$ temperature, i.e., the temperature at which tensile straining to $30 \%$ induces $50 \%$ volume fraction of $\alpha^{\prime}$ martensite, is calculated to be $21{ }^{\circ} \mathrm{C}$ according to the formula proposed by Nohara et al. [24]: $\mathrm{Md}_{30}\left({ }^{\circ} \mathrm{C}\right)=551-462(\mathrm{C}+\mathrm{N})-$ $9.2 \mathrm{Si}-8.1 \mathrm{Mn}-29(\mathrm{Ni}+\mathrm{Cu})-13.7 \mathrm{Cr}-18.5 \mathrm{Mo}(\mathrm{wt} \%)$, confirming that pre-straining at room temperature may induce $\alpha^{\prime}$ martensite transformation in the steel. Tensile specimens with a gauge size of 25 (length) $\times 10$ (width) $\times 2$ (thickness) $\mathrm{mm}^{3}$ were cut from the plate with their length direction parallel to the rolling direction. The specimen surfaces were ground with successive grades of emery paper up to 2000 grit, polished with paste, washed with deionized water and dried. Tensile plastic pre-strains were applied to the specimens along the length direction by tension at $20,50,80$ and $100{ }^{\circ} \mathrm{C}$, respectively, at a strain rate of $2.5 \times 10^{-4} \mathrm{~s}^{-1}$ using a tensile testing machine with a heating furnace. The specimens are firstly heated to the required temperature slowly $\left(\sim 5^{\circ} \mathrm{C} / \mathrm{min}\right)$ and then they were clamped and pre-strained. The plastic pre-strain level was set as $30 \pm 2 \%$ (nominal strain), as this strain level is high enough to cover the strain range usually used in the cold-stretching technique. 
To identify the $\alpha^{\prime}$ martensite transformation, the microstructures of both un-pre-strained and pre-strained specimens were examined by an optical microscope $(\mathrm{OM})$ after etching by the Beraha's reagent $(0.5 \mathrm{~g}$ potassium metabisulfite, $20 \mathrm{~mL} \mathrm{HCl}$ and $100 \mathrm{~mL}$ distilled water) according to [25]. The phase identification and quantitative estimate of phase volume fractions were further determined by the X-ray diffraction (XRD) technique. The XRD measurements were conducted with a $2 \theta$ range from $40^{\circ}$ to $100^{\circ}$ at room temperature using a diffractometer (Rigaku SmartLab, Tokyo, Japan) with a Cu-K $\alpha$ $(\lambda=0.154056 \mathrm{~nm})$ radiation operating at $40 \mathrm{kV}$ and $30 \mathrm{~mA}$ at a step size of $0.02^{\circ}$. The quantitative estimation of phases by XRD is based on the principle that the total integrated intensity of all diffraction peaks for each phase in a mixture is proportional to the volume fraction of that phase $[22,26,27]$. For an ASS containing $\gamma$ austenite (fcc), $\alpha^{\prime}$ martensite (bcc) and $\varepsilon$ martensite (hcp), by considering the $(220)_{\gamma},(311)_{\gamma},(111)_{\gamma}$, and $(200)_{\gamma}$ reflections for $\gamma$ austenite, $(200)_{\alpha^{\prime}},(211)_{\alpha^{\prime}}$ and $(110)_{\alpha^{\prime}}$ reflections for $\alpha^{\prime}$ martensite, and $(101)_{\varepsilon}$ and $(102)_{\varepsilon}$ for $\varepsilon$ martensite, the volume fraction of austenite and martensite can be derived from the numerous peaks by the following formula:

$$
V_{i}=\frac{\frac{1}{n} \sum_{j=1}^{n} \frac{I_{i}^{j}}{R_{i}^{j}}}{\frac{1}{n} \sum_{j=1}^{n} \frac{I_{\gamma}^{j}}{R_{\gamma}^{j}}+\frac{1}{n} \sum_{j=1}^{n} \frac{I_{\alpha^{\prime}}^{j}}{R_{\alpha^{\prime}}^{j}}+\frac{1}{n} \sum_{j=1}^{n} \frac{I_{\varepsilon}^{j}}{R_{\varepsilon}^{j}}}
$$

where $i=\gamma, \alpha^{\prime}$ or $\varepsilon, n$ is the number of peaks of the phase examined, $I_{i}$ and $R_{i}$ are the integrated intensity of reflecting plane and material scattering factor, respectively. Each $R_{i}$ value used was obtained from Ref. [26]. In our previous study [28], we have used the magnetic induction method (the $\alpha^{\prime}$ martensite is ferromagnetic) to verify the XRD method used, and found that the two methods are comparable in detecting the presence of $\alpha^{\prime}$ martensite.

The specimens were then cathodically charged with hydrogen in $0.1 \mathrm{~mol} / \mathrm{L} \mathrm{NaOH}$ solution at a current density of $1.1 \mathrm{~mA} / \mathrm{cm}^{2}$ for $48 \mathrm{~h}$ at $50{ }^{\circ} \mathrm{C}$. When the hydrogen-charging was completed, the specimens were taken to tensile testing in air within $5 \mathrm{~min}$ also at the strain rate of $2.5 \times 10^{-4} \mathrm{~s}^{-1}$ by the tensile testing machine. Two replicated specimens were used for each testing condition. The specimens un-charged were also tested as references. Tensile curves and properties were obtained. The HE index, namely, the plasticity loss

$$
\delta_{\mathrm{L}}=\left(\delta_{0}-\delta_{\mathrm{H}}\right) / \delta_{0}
$$

where $\delta_{0}$ and $\delta_{\mathrm{H}}$ are the elongation at fracture of un-charged and charged specimens, respectively, was used to quantitatively evaluate the HE susceptibility. The HE susceptibility increases with increasing $\delta_{\mathrm{L}}$. The fracture surfaces of broken specimens were examined by a scanning electron microscope (SEM, JEOL JSM-6510, JEOL Ltd., Tokyo, Japan). In addition, an extra group of specimens was pre-strained and hydrogen-charged, and then the total hydrogen amounts charged into the specimens by the hydrogen-charging were determined by the inert gas impulse fusion heat conductivity method using a hydrogen-oxygen-nitrogen analyzer (LECO ONH836, LECO Corporation, St. Joseph, MI, USA).

\section{Results and Discussion}

The OM microstructures and XRD results are shown in Figures 1 and 2, respectively. The un-pre-strained specimens have a typical microstructure of solution-annealed ASSs, i.e., composed of nearly-equiaxed grains of austenite and annealing twins, see Figure 1a, and no $\alpha^{\prime}$ martensite diffraction peak was detected (a $\varepsilon$ martensite peak with a lower intensity was detected), see Figure 2a, indicating an almost full single-phase austenite microstructure. In contrast, the specimens pre-strained at $20^{\circ} \mathrm{C}$ exhibit severe strain-induced $\alpha^{\prime}$ martensite transformation, as indicated in Figure $1 \mathrm{~b}$ by the etched dark regions $[22,25,27]$ and Figure $2 a$ by the presence of great $\alpha^{\prime}$ martensite diffraction peaks. Figure $2 \mathrm{~b}$ shows an average volume fraction of $\alpha^{\prime}$ martensite of $40.5 \%$ in the $20{ }^{\circ} \mathrm{C}$ pre-strained 
specimens, indicating that nearly half of the specimens were transformed into $\alpha^{\prime}$ martensite. However, the specimens pre-strained at $50^{\circ} \mathrm{C}$ suffered from less severe $\alpha^{\prime}$ martensite transformation, as indicated in Figure 2a by the lower intensity of $\alpha^{\prime}$ martensite diffraction peaks and Figure $2 \mathrm{~b}$ by the volume fraction of $\alpha^{\prime}$ martensite of $8.1 \%$. Furthermore, it is found that the specimens pre-strained at 80 and $100{ }^{\circ} \mathrm{C}$ demonstrated almost no strain-induced $\alpha^{\prime}$ martensite transformation, see Figures $1 \mathrm{c}$ and 2. Thus, the results clearly indicate that the higher temperatures can effectively suppress the $\alpha^{\prime}$ martensite transformation during the pre-strain, in agreement with [21-23], and the higher the temperature at which the pre-strain is applied the less severe the $\alpha^{\prime}$ martensite transformation is induced. In addition, in these pre-strained specimens, parallel or intersecting slip bands were also shown, evdicing the occurance of palstic deformation, see Figure 1.

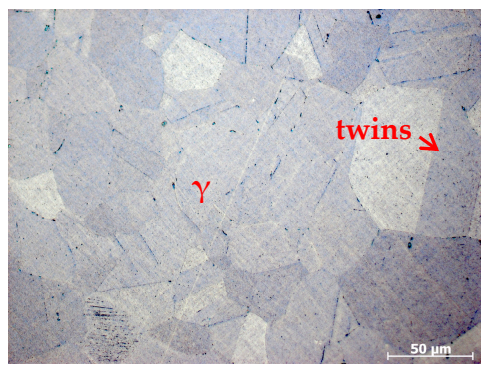

(a)

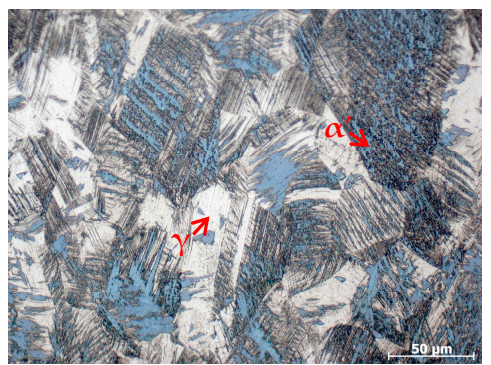

(b)

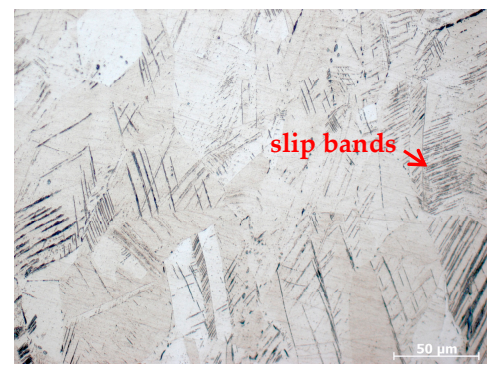

(c)

Figure 1. Microstructures of specimens: (a) Un-pre-strained; (b) $30 \%$ pre-strained at $20{ }^{\circ} \mathrm{C}$; (c) $30 \%$ pre-strained at $80{ }^{\circ} \mathrm{C}$.
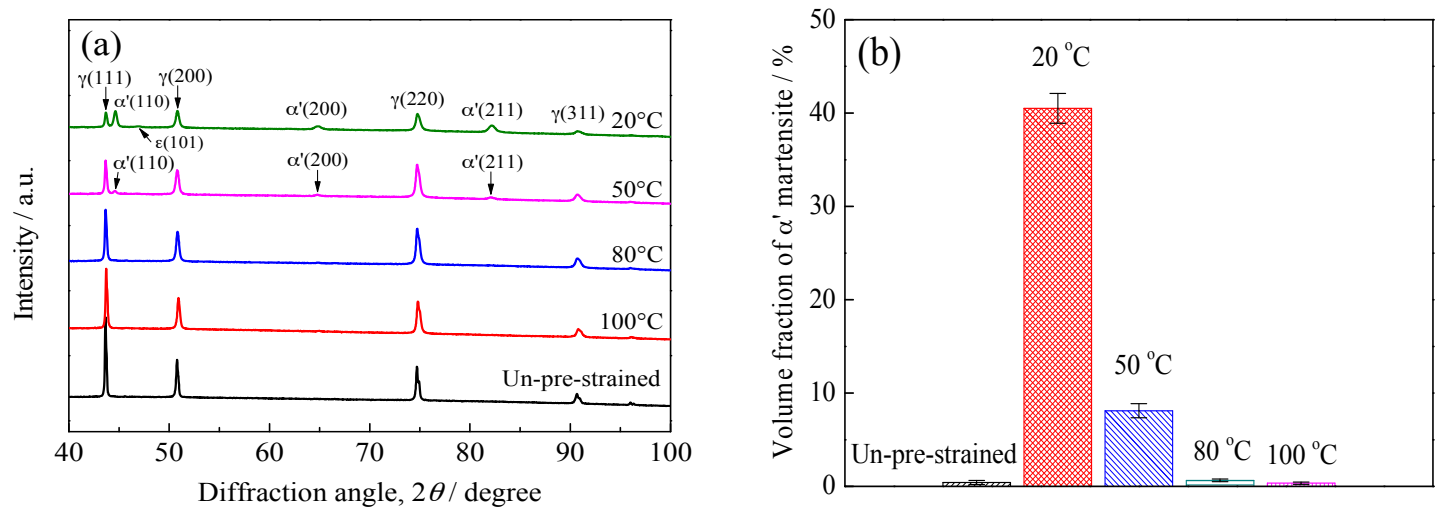

Figure 2. X-ray diffraction (XRD) results of specimens: (a) The XRD patterns; (b) The volume fraction of $\alpha^{\prime}$ martensite.

Figure 3 shows the representative stress-strain curves. The 30\% pre-strain significantly elevated the yield strength and tensile strength but reduced the elongation at fracture of the un-charged specimens, particularly at $20{ }^{\circ} \mathrm{C}$, indicating that the strain-strengthening of $304 \mathrm{~L}$ steel depends on the strain temperature. For example, after $30 \%$ pre-strain at $20^{\circ} \mathrm{C}$, the yield strength increased from 265 to $850 \mathrm{MPa}$ by 3.2 times. At $50{ }^{\circ} \mathrm{C}$, it increased to $785 \mathrm{MPa}$ by 3 times and at $80{ }^{\circ} \mathrm{C}$ to $720 \mathrm{MPa}$ by 2.7 times. The mechanism of strain-strengthening of ASSs has been well-established in literatures, e.g., $[22,29,30]$. It should be noted that, for the metastable ASSs, the strain-induced $\alpha^{\prime}$ martensite transformation also plays a role, since not only it is inherently harder but also it can induce an excess increase in dislocation density to accommodate the volume expansion and can act as obstacles for slip. Thus, the strain-strengthening at room temperature was more significant due to the $\alpha^{\prime}$ martensite transformation. However, it can be found that the gaps between these strength values for the three temperatures are marginal, indicating that pre-straining the steel warmly, i.e., at a temperature slightly higher than room temperature, can still strengthen the $304 \mathrm{~L}$ steel by a very large degree, although the $\alpha^{\prime}$ martensite transformation is suppressed. 


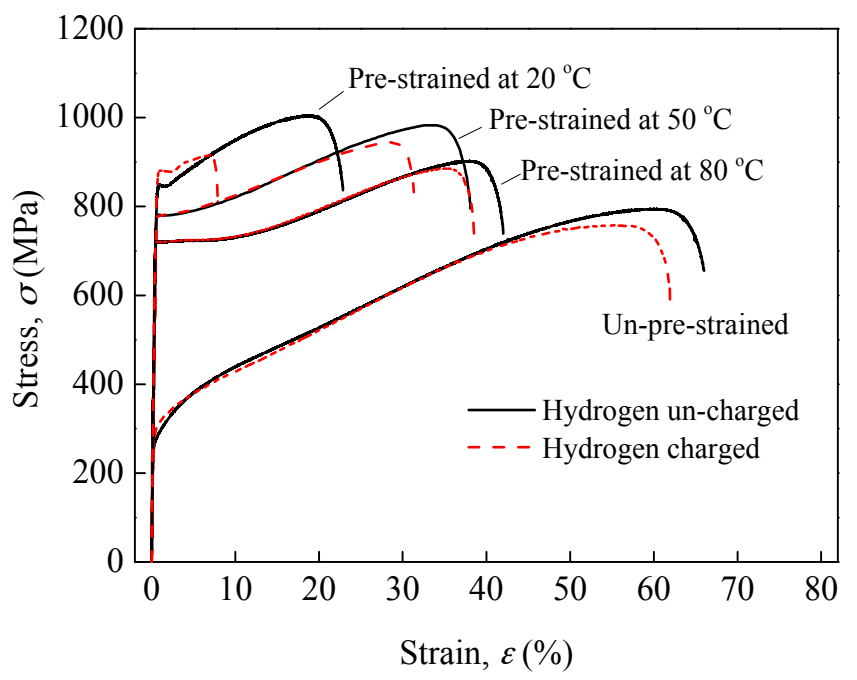

Figure 3. Nominal stress-strain curves of specimens.

Figure 3 shows that the hydrogen-charging had limited influence on the yield strength of all specimens, but decreased the tensile strength and elongation at fracture, indicating a loss in plasticity due to hydrogen-charging, i.e., HE. Figure 4 plots the average HE index $\delta_{\mathrm{L}}$ calculated for the specimens. The $\delta_{\mathrm{L}}$ of un-pre-strained specimens is $6.1 \%$, which is very low indicating the good HE resistance of $304 \mathrm{~L}$ steel without pre-strain, i.e., at the solution-annealed state, whereas after pre-strain at $20^{\circ} \mathrm{C}$, the $\delta_{\mathrm{L}}$ was increased by more than 10 times, i.e., was increased to $64.1 \%$, meaning that the $20{ }^{\circ} \mathrm{C}$ pre-strain significantly increased the HE susceptibility of the $304 \mathrm{~L}$ steel. Clearly, this significant increase in HE susceptibility can be preferentially related to the pre-existence of a large volume fraction of $\alpha^{\prime}$ martensite induced by the $20^{\circ} \mathrm{C}$ pre-strain, as noted by the authors [16-19]. However, for the specimens pre-strained at $50{ }^{\circ} \mathrm{C}$, the $\delta_{\mathrm{L}}$ is $17.4 \%$, and for the specimens pre-strained at 80 and $100{ }^{\circ} \mathrm{C}$, the $\delta_{\mathrm{L}}$ are $8.2 \%$ and $6.3 \%$, respectively, indicating that the warm pre-strains did not enhance the HE susceptibility of the $304 \mathrm{~L}$ steel, particularly the 80 and $100{ }^{\circ} \mathrm{C}$ pre-strains. This result can be attributed to that the higher temperatures had suppressed the $\alpha^{\prime}$ martensite transformation during the pre-strain. Figure 5 depicts the HE index $\delta_{\mathrm{L}}$ as a function of pre-strain-induced $\alpha^{\prime}$ martensite volume fraction. Evidently, regardless of the pre-strain temperature, the HE susceptibility of the steel almost linearly increases with increasing pre-existing $\alpha^{\prime}$ martensite amount.

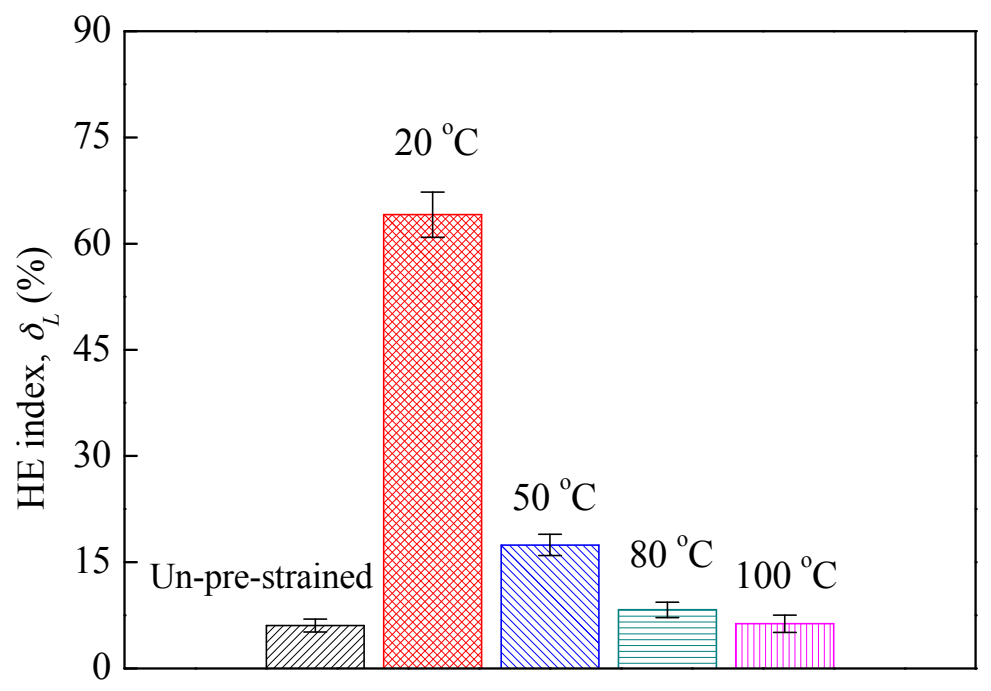

Figure 4. Hydrogen embrittlement (HE) index of hydrogen-charged specimens. 


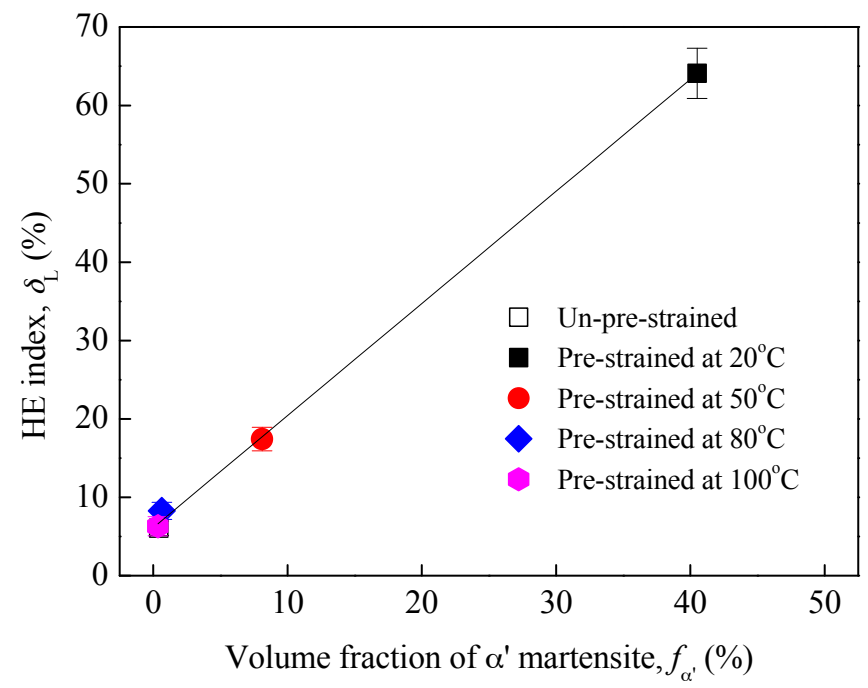

Figure 5. HE index as a function of pre-existing $\alpha^{\prime}$ martensite.

Turning to the SEM morphologies of the fracture surfaces, all specimens without hydrogen-charging exhibit dimples on their whole fracture surfaces, revealing a ductile fracture. However, all hydrogen-charged specimens show two zones with different fracture features, i.e., the central regions show dimples, but the edge regions, where the materials were exposed to hydrogen during hydrogen-charging, show transgranular quasi-cleavage (QC) fracture with some flat facets (FFs) and secondary cracks (SCs). As examples, Figure 6 shows the results of specimens un-pre-strained and pre-strained at 20 and $80{ }^{\circ} \mathrm{C}$, respectively. In fact, this fracture feature of edge regions has been well-established as the typical mode of hydrogen-induced brittle fracture in hydrogenated metastable ASSs [6-9]. The formation of flat facets can be related to the twin boundary separations [6-9]. However, the SCs in the $20^{\circ} \mathrm{C}$ pre-strained specimens are more and bigger (wider and longer), indicating a more severe HE. For example, the widths of some SCs presenting in the $20^{\circ} \mathrm{C}$ pre-strained specimens, see Figure $6 \mathrm{~d}$, exceed $10 \mu \mathrm{m}$, but the widths of the SCs in the un-pre-strained and $80{ }^{\circ} \mathrm{C}$ pre-strained specimens, see Figure $6 \mathrm{~b}, \mathrm{f}$, do not exceed $6 \mu \mathrm{m}$.
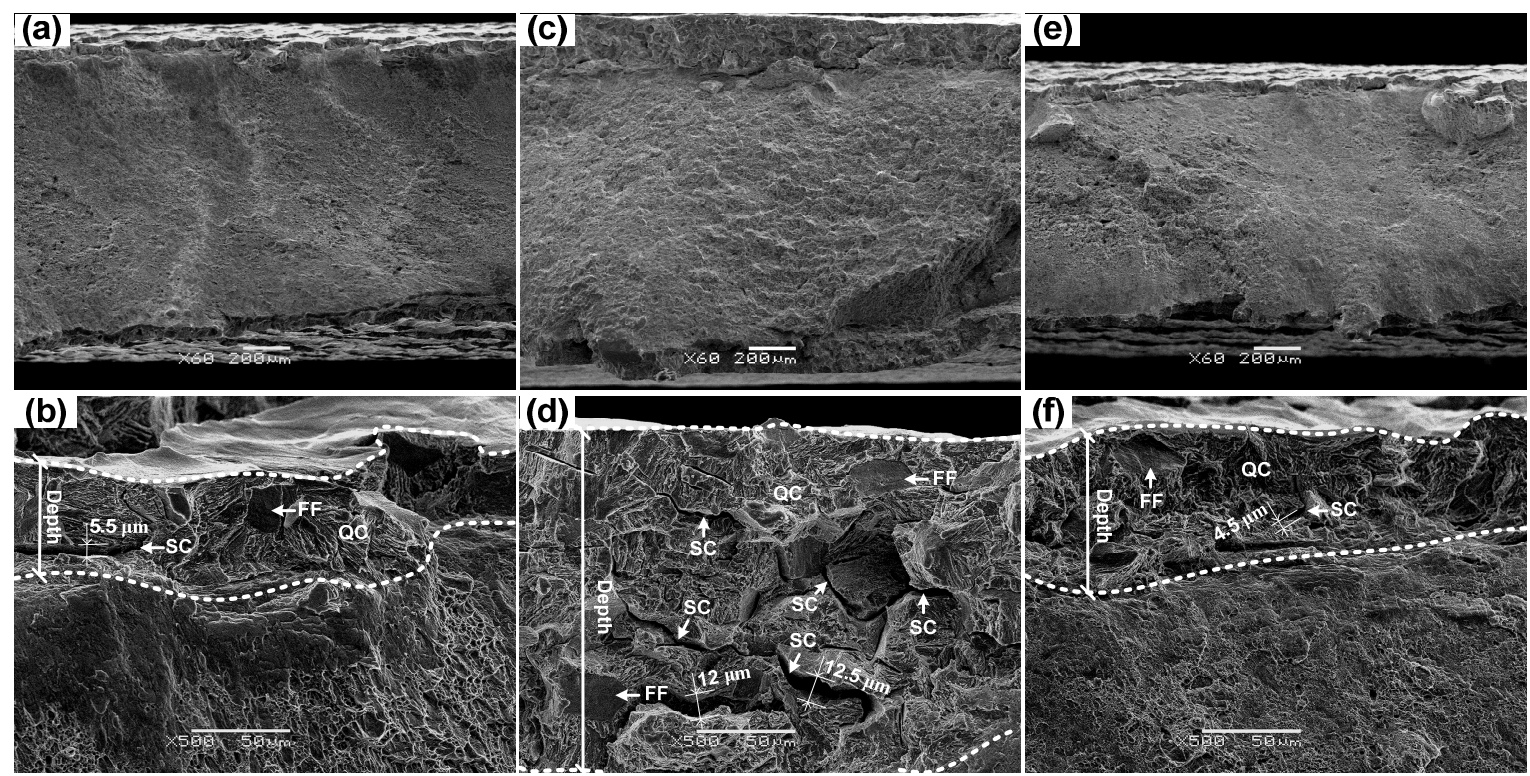

Figure 6. SEM fracture surfaces of broken specimens. (a,b) Un-pre-strained; (c,d) Pre-strained at $20^{\circ} \mathrm{C}$; $(\mathbf{e}, \mathbf{f})$ Pre-strained at $80^{\circ} \mathrm{C}$. 
It is found that the depth of brittle fracture regions varies with the pre-strain temperature. The $20{ }^{\circ} \mathrm{C}$ pre-strained specimens have a largest brittle region depth. The depth of brittle fracture region can roughly represent the maximum distance of hydrogen transporting into the specimen during the hydrogen exposure, thus it can be used to approximately evaluate the apparent hydrogen diffusivity. For the plate-type specimen, according to Fick's law, the distribution of hydrogen along the depth direction during charging can be formalized by $[18,31-33]$

$$
c(x, t)=c_{\mathrm{i}}+\left(c_{\mathrm{s}}-c_{\mathrm{i}}\right)\left[1-\operatorname{erf}\left(\frac{x}{2 \sqrt{D t}}\right)\right]
$$

where $x$ is the depth from the specimen surface; $c_{\mathrm{i}}$ is the initial hydrogen concentration in the specimen, which is taken as zero here since the hydrogen amount measurement results show a negligible hydrogen amount in the un-charged specimens; $c_{\mathrm{S}}$ is the hydrogen concentration dissolved at the specimen surface during the charging; $D$ is the apparent diffusivity of hydrogen; $t$ is the charging time. Since when $x / 2 \sqrt{D t} \geq 2, c$ approaches to 0 , the maximum hydrogen transport distance $x_{\max }$ can be determined approximately by taking $x_{\max }=4 \sqrt{D t}[20,31,32]$. Based on this equation, the $D$ is calculated as $7.6 \times 10^{-16} \mathrm{~m}^{2} / \mathrm{s}$ for the un-pre-strained specimens (this value is in good agreement with those reported previously in $[2,17,33]$ for solution-annealed ASSs, i.e., $1.8-8.0 \times 10^{-16} \mathrm{~m}^{2} / \mathrm{s}$ ), and $1.7 \times 10^{-14}, 2.8 \times 10^{-15}, 10.1 \times 10^{-16}, 9.4 \times 10^{-16} \mathrm{~m}^{2} / \mathrm{s}$ for the $30 \%$ pre-strained specimens at 20 , 50,80 and $100{ }^{\circ} \mathrm{C}$, respectively. It is indicated that, compared with the un-pre-strained specimens, the $30 \%$ pre-strain at $20{ }^{\circ} \mathrm{C}$ increased the diffusivity by about 22 times, and the $30 \%$ pre-strain at $50{ }^{\circ} \mathrm{C}$ increased the diffusivity by 4 times, while the $30 \%$ pre-strain at 80 and $100{ }^{\circ} \mathrm{C}$ had almost no influence on the diffusivity. This result corresponds to that a large amount of $\alpha^{\prime}$ martensite had formed in the $20^{\circ} \mathrm{C}$ pre-strained specimens, while only a little $\alpha^{\prime}$ martensite had formed in the $50^{\circ} \mathrm{C}$ specimens and almost no $\alpha^{\prime}$ martensite had formed in the 80 and $100{ }^{\circ} \mathrm{C}$ specimens. It has been established that the pre-existing $\alpha^{\prime}$ martensite induced by pre-strain in ASSs can provide "highways" for hydrogen diffusion and transport [7-9]. Since there was a large volume fraction of $\alpha^{\prime}$ martensite pre-existing in the $20^{\circ} \mathrm{C}$ pre-strained specimens, the apparent diffusivity of hydrogen was markedly increased. Consequently, the hydrogen transported into the specimens by a very deep depth during hydrogen-charging, resulting in severe $\mathrm{HE}$ for the $20^{\circ} \mathrm{C}$ pre-strained specimens. There was only $8.1 \% \alpha^{\prime}$ martensite pre-existing in the $50^{\circ} \mathrm{C}$ pre-strained specimens, thus the specimens have a HE susceptibility just slightly higher than the un-pre-strained specimens. For the specimens pre-strained at 80 and $100^{\circ} \mathrm{C}$, since the $\alpha^{\prime}$ martensite was almost completely suppressed, the specimens still mainly composed of single-phase austenite after pre-straining, consequently the diffusivity of hydrogen was nearly unchanged, and the specimens retained its good resistance to the HE.

The total hydrogen amounts charged into the specimens are shown in Figure 7 as a function of pre-strain-induced $\alpha^{\prime}$ martensite. The results confirm that the $\alpha^{\prime}$ martensite can provide "highways" for the hydrogen to transport into the specimens. There was a large volume fraction of $\alpha^{\prime}$ martensite in the $20 \%$ pre-strained specimens, and the diffusivity of hydrogen in the specimens was increased, thus the total hydrogen amount transporting into the specimens was very high. Moreover, regardless of pre-strain temperature, with increasing volume fraction of pre-strain-induced $\alpha^{\prime}$ martensite, the total hydrogen amount charged into the specimens increased. However, it should be noted that this increase became less significant with increasing $\alpha^{\prime}$ martensite, this is because the $\alpha^{\prime}$ martensite possesses lower hydrogen solubility. The increase in $\alpha^{\prime}$ martensite resulted in a decrease in apparent hydrogen solubility, thus the total hydrogen amounts charged into the specimens decreased. 


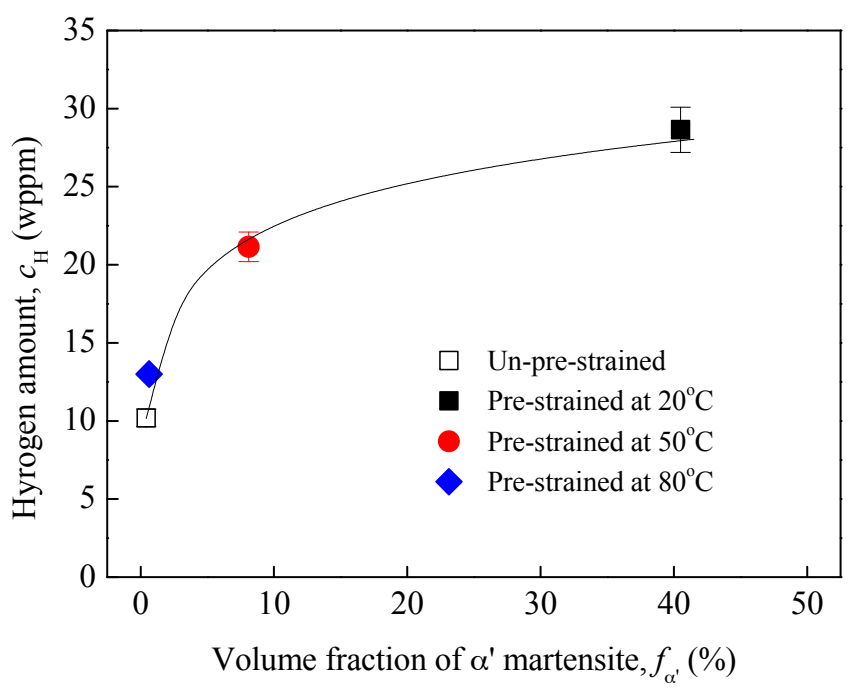

Figure 7. Total hydrogen amounts charged into the steel as a function of pre-existing $\alpha^{\prime}$ martensite.

The results show that, the 50,80 and $100{ }^{\circ} \mathrm{C}$ pre-strains can still strengthen the $304 \mathrm{~L}$ steel by a very large degree, thus it can be concluded that the warm pre-strain has a potential to strengthen the metastable ASSs without compromising their excellent HE resistance before pre-strain, i.e., at the solution-annealed state. For example, for an ASS pressure vessel to be exposed to a hydrogen-containing environment during service, e.g., high pressure gaseous hydrogen, if we pressurize it warmly, i.e., at a temperature slightly higher than room temperature, e.g., $80{ }^{\circ} \mathrm{C}$ for the 304L steel, during the application of "cold"-stretching technique, on one hand, we can still strengthen the vessel (although the strengthening effect is not as significant as the stretching at room temperature or lower temperature), consequently using reduced wall thickness and weight to withstand the pressure, on the other hand, we can still expect a higher HE resistance for the vessel, as the $\alpha^{\prime}$ martensite transformation is suppressed by the warm-stretching.

\section{Conclusions}

This paper investigated the effect of 30\% tensile pre-strain applied respectively at 20 (room temperature), 50, 80 and $100{ }^{\circ} \mathrm{C}$ on the $\mathrm{HE}$ resistance of metastable $304 \mathrm{~L}$ austenitic stainless steel. The main conclusions are as follows:

(1) The $30 \%$ pre-strain at $20{ }^{\circ} \mathrm{C}$ significantly elevates the strength of $304 \mathrm{~L}$ steel, whereas it also induces a large volume fraction of $\alpha^{\prime}$ martensite in the steel. Since the pre-existing $\alpha^{\prime}$ martensite can provide "highways" for the hydrogen to transport into the steel during subsequent hydrogen exposure, the pre-strained steel exhibits severe HE. The HE resistance of 304L steel can be markedly impaired by the room temperature pre-strain.

(2) In the $304 \mathrm{~L}$ steel, the $30 \%$ pre-strain at $50{ }^{\circ} \mathrm{C}$ induces a little amount of $\alpha^{\prime}$ martensite, and those at 80 and $100{ }^{\circ} \mathrm{C}$ induce almost no $\alpha^{\prime}$ martensite. Since the $\alpha^{\prime}$ martensite transformation is suppressed by the higher temperatures, particularly the 80 and $100{ }^{\circ} \mathrm{C}$, the subsequent $\mathrm{HE}$ resistance of $304 \mathrm{~L}$ steel is not impaired. When pre-straining a metastable ASS, elevating slightly the temperature helps preserve the HE resistance of the steel.

(3) Although the strengthening effect of the pre-strains at 50,80 and $100{ }^{\circ} \mathrm{C}$ is not as significant as the pre-strain at room temperature, i.e., $20^{\circ} \mathrm{C}$, they can still strengthen the $304 \mathrm{~L}$ steel by a very large degree, thus, we can apply the warm pre-strain, e.g., $80^{\circ} \mathrm{C}$ for the $304 \mathrm{~L}$ steel, to strain-strengthen the metastable ASSs, reducing the weight and cost of components but without compromising their original good HE resistance. 
Acknowledgments: This work is supported by the Fundamental Research Funds for the Central Universities of China (2015QNA20).

Author Contributions: Yanfei Wang and Jianming Gong conceived and designed the experiments; Yanfei Wang, Zhiling Zhou and Weijie Wu performed the experiments and analyzed the data; Jianming Gong contributed reagents/materials/analysis tools; Yanfei Wang and Zhiling Zhou wrote the paper; Jianming Gong provided corrections on the manuscript.

Conflicts of Interest: The authors declare no conflict of interest.

\section{References}

1. Zheng, J.; Liu, X.; Xu, P.; Liu, P.; Zhao, Y.; Yang, J. Development of high pressure gaseous hydrogen storage technologies. Int. J. Hydrog. Energy 2012, 37, 1048-1057. [CrossRef]

2. San Marchi, C. Technical Reference on Hydrogen Compatibility of Materials: Austenitic Stainless Steels, Type 304 \& 304L. Available online: http: / / public.ca.sandia.gov/matlsTechRef/ chapters /2101TechRef_304SS. pdf (accessed on 12 October 2017).

3. Borchers, C.; Michler, T.; Pundt, A. Effect of hydrogen on the mechanical properties of stainless steels. Adv. Eng. Mater. 2008, 10, 11-23. [CrossRef]

4. Eliezer, D.; Chakrapani, D.G.; Altstetter, C.J.; Pugh, E.N. The influence of austenite stability on the hydrogen embrittlement and stress-corrosion cracking of stainless steel. Metall. Trans. A 1979, 10, 935-941. [CrossRef]

5. Perng, T.P.; Altstetter, C.J. Hydrogen effects in austenitic stainless steels. Mater. Sci. Eng. A 1990, 129, 99-107. [CrossRef]

6. Han, G.; He, J.; Fukuyama, S.; Yokogawa, K. Effect of strain induced martensite on hydrogen environment embrittlement of sensitized austenitic stainless steels at low temperatures. Acta Mater. 1998, 46, 4559-4570. [CrossRef]

7. Zhang, L.; Li, Z.; Zheng, J.; Zhao, Y.; Xu, P.; Zhou, C.; Li, X. Effect of strain-induced martensite on hydrogen embrittlement of austenitic stainless steels investigated by combined tension and hydrogen release methods. Int. J. Hydrog. Energy 2013, 38, 8208-8214. [CrossRef]

8. Kanezaki, T.; Narazaki, C.; Mine, Y.; Matsuoka, S.; Murakami, Y. Effects of hydrogen on fatigue crack growth behavior of austenitic stainless steels. Int. J. Hydrog. Energy 2008, 33, 2604-2619. [CrossRef]

9. Chen, T.C.; Chen, S.T.; Tsay, L.W. The role of induced $\alpha^{\prime}$-martensite on the hydrogen-assisted fatigue crack growth of austenitic stainless steels. Int. J. Hydrog. Energy 2014, 39, 10293-10302. [CrossRef]

10. Michler, T.; Naumann, J. Hydrogen environment embrittlement of austenitic stainless steels at low temperatures. Int. J. Hydrog. Energy 2008, 33, 2111-2122. [CrossRef]

11. Barthélémy, H. Hydrogen storage-Industrial prospectives. Int. J. Hydrog. Energy 2012, 37, $17364-17372$. [CrossRef]

12. Zheng, J.; Miao, C.; Li, Y.; Xu, P.; Ma, L.; Guo, A. Investigation on influence factors of mechanical properties of austenitic stainless steels for cold stretched pressure vessels. J. Press. Vessel Technol. 2012, 134, 061407. [CrossRef]

13. Tang, L.; Qian, C.; Wang, Z.; Li, H. Experimental study of the strain-strengthening effect on the mixed mode notch-crack fatigue propagation in austenitic stainless steel 06Cr19Ni10. Eng. Fract. Mech. 2015, 134, 54-60. [CrossRef]

14. Cryogenic Vessels—Static Vacuum Insulated Vessels. Part 2: Design, Fabrication, Inspection and Testing, Appendix C; EN 13458-2:2002; British Standards Institution: London, UK, 2002.

15. Pressure Vessels Cold-Stretched Austenitic Stainless Steel Vessels; AS 1210 Supplement 2; Standards Australia: Sydney, Australia, 1999.

16. ASME. Rules for Construction of Pressure Vessels, Appendix: 2011, Case 2596: Cold-Stretching of Austenitic Stainless Steel Pressure Vessels; ASME BPVC, VIII Division 1; ASME: New York, NY, USA, 2010.

17. Perng, T.P.; Altstetter, C.J. Effects of deformation on hydrogen permeation in austenitic stainless steels. Acta Metall. 1986, 34, 1771-1781.

18. Mine, Y.; Narazaki, C.; Murakami, K.; Matsuoka, S.; Murakami, Y. Hydrogen transport in solution-treated and pre-strained austenitic stainless steels and its role in hydrogen-enhanced fatigue crack growth. Int. J. Hydrog. Energy 2009, 34, 1097-1107. [CrossRef] 
19. Martin, M.; Weber, S.; Izawa, C.; Wagner, S.; Pundt, A.; Theisen, W. Influence of machining-induced martensite on hydrogen assisted fracture of AISI 304 type 304 austenitic stainless steel. Int. J. Hydrog. Energy 2011, 36, 11195-11206. [CrossRef]

20. Wang, Y.; Wang, X.; Gong, J.; Shen, L.; Dong, W. Hydrogen embrittlement of catholically hydrogen-precharged 304L austenitic stainless steel: Effect of plastic pre-strain. Int. J. Hydrog. Energy 2014, 39, 13909-13918. [CrossRef]

21. Talonen, J.; Hänninen, H. Formation of shear bands and strain-induced martensite during plastic deformation of metastable austenitic stainless steels. Acta Mater. 2007, 55, 6108-6118. [CrossRef]

22. De, A.K.; Speer, J.G.; Matlock, D.K.; Murdock, D.C.; Mataya, M.C.; Comstock, R.C., Jr. Deformation-induced phase transformation and strain hardening in type 304 austenitic stainless steel. Metall. Mater. Trans. A 2006, 37, 1875-1886. [CrossRef]

23. Spencer, K.; Véron, M.; Zhang, K.Y.; Embury, J.D. The strain induced martensite transformation in austenitic stainless steels: Part 1-Influence of temperature and strain history. Mater. Sci. Technol. 2009, 25, 7-17. [CrossRef]

24. Nohara, K.; Ono, Y.; Ohash, Y.N.J. Composition and grain size dependencies of strain-induced martensitic transformation in metastable austenitic stainless steels. Iron Steel Inst. Jpn. 1977, 63, 212-222. [CrossRef]

25. Ahmadzade-Beiraki, E.; Mazinani, M.; Kashefi, M. Examination of Barkhausen noise parameters for characterisation of strain-induced martensitic transformation in AISI 304 stainless steel. Insight 2016, 58, 297-301. [CrossRef]

26. Cullity, B.D. Elements of X-ray Diffraction; Addison-Wesley Publishing Company: Reading, MA, USA, 1978.

27. De, A.K.; Murdock, D.C.; Mataya, M.C.; Speer, J.G.; Matlock, D.K. Quantitative measurement of deformation-induced martensite in 304 stainless steel by X-ray diffraction. Scr. Mater. 2004, 50, 1445-1449. [CrossRef]

28. Peng, Y.; Gong, J.; Jiang, Y.; Fu, M.; Rong, D. The effect of plastic pre-strain on low-temperature surface carburization of AISI 304 austenitic stainless steel. Surf. Coat. Technol. 2016, 304, 16-22. [CrossRef]

29. Byun, T.S.; Hashimoto, N.; Farrell, K. Temperature dependence of strain hardening and plastic instability behaviors in austenitic stainless steels. Acta Mater. 2004, 52, 3889-3899. [CrossRef]

30. Fang, X.F.; Dahl, W. Strain hardening and transformation mechanism of deformation-induced martensite transformation in metastable austenitic stainless steels. Mater. Sci. Eng. 1991, 141, 189-198. [CrossRef]

31. Crank, J. The Mathematics of Diffusion; Oxford: Clarendon, UK, 1975.

32. Zhu, W.Y.; Qiao, L.J.; Li, J.X.; Su, Y.J.; Yan, Y.; Bai, Y.; Ren, X.C.; Huang, H.Y. Hydrogen Embrittlement and Stress Corrosion Cracking; Science Press: Beijing, China, 2013.

33. Olden, V.; Thaulow, C.; Johnsen, R. Modelling of hydrogen diffusion and hydrogen induced cracking in supermartensitic and duplex stainless steels. Mater. Des. 2008, 29, 1934-1948. [CrossRef] 